\title{
A CRITICAL APPROACH TO SENSORIMOTOR CONTINGENCY THEORY: BRAIN AS AGENT AND CONSCIOUS MIND AS A GUIDE OF ACTION
}

\author{
UMA ABORDAGEM CRIITICA À TEORIA DA CONTINGÊNCIA SENSORIOMOTORA: \\ O CÉREBRO COMO AGENTE E A MENTE CONSCIENTE COMO GUIA DE AÇAO
}

\begin{abstract}
I present and consider critically O'Regan and Noë's sensorimotor contingency theory, proposed as an alternative to solve the explanatory gap problem. I start with the criticism that these authors address the current conception of representation, according to which conscious experiences are representations of the external world produced by the brain. Afterward, I summarize the way the sensorimotor contingency theory addresses the problem of the explanatory gap, explaining the existence, form, and content of visual consciousness in terms of an "exploratory activity" mediated by sensorimotor contingency laws. Finally, in agreement with criticisms addressed to O'Regan and Noë's solution, I propose a way to face the problem of the explanatory gap, which, recognizing the relevance of the body and the external environment to the existence, form and content of visual consciousness, but privileging the role of the brain as an organ of visual consciousness, and as an agent who uses visual consciousness as a guide to initiate and maintain embodied and situated adaptive actions in the world.
\end{abstract}

KEYWORDS: O'Regan and Noë. Sensorimotor contingency theory. Explanatory gap. Qualia. Agent brain. Consciousness guide of action.

RESUMO: O objetivo é apresentar e refletir criticamente sobre a teoria da contingência sensoriomotora proposta por O'Regan and Noë para resolver o problema da lacuna explicativa. Começo pela crítica que esses autores dirigem à concepção representacionista corrente segundo a qual as experiências conscientes seriam representaçôes do mundo externo produzidas pelo cérebro. A seguir, apresento, resumidamente, o modo como a teoria da contingência sensóriomotora enfrenta o problema da lacuna explicativa explicando a existência, forma e conteúdo da consciência visual em termos de uma "atividade exploratória" mediada pelas de leis da contingência sensoriomotora. Por fim, em acordo com as críticas de alguns comentadores à solução proposta por O'Regan and Noë, aponto um caminho para enfrentar esse problema, o qual, embora ressaltando o papel indispensável do corpo e do ambiente externo ao corpo na geração das formas e conteúdos da consciência visual, privilegia o cérebro como órgão da consciência visual e da mente consciente em geral, e como o agente que usa sua consciência visual como guia para iniciar e manter ações adaptativas no ambiente em que vive.

PALAVRAS-CHAVE: O'Regan and Noë. Teoria da contingência sensório-motora. Lacuna explicativa. Qualia. Cérebro agente. Consciência guia de ação.

\footnotetext{
${ }^{1}$ Departamento de Ciências Humanas da UNESP de Bauru e Programa de Pós-Graduação em Filosofia da UNESP de Marília.
} 


\section{TRADIIIONAL APPROACH TO VISUAL CONSCIOUSNESS, QUALIA AND THE EXPLANATORY GAP}

\section{1}

In a challenging paper published in 2001, followed by peer commentaries and authors' responses, "The sensorimotor account of vision and visual consciousness", Kevin O'Regan and Alva Noë propose to answer the following question: "What is visual experience and where does it occur?" (2001, p. 939). From the beginning and throughout the article, they criticize what would be the current neurophysiological, psychophysical, and psychological approach to vision, that is, the idea that "when we see, the brain produces an internal representation of the world" and it is the "activation of this internal representation" that is supposed "to give rise to the experience of seeing" (2001, p. 939). More precisely, O'Regan and Noë criticize both ideas, that "somewhere in the brain an internal representation of the outside world must be set up which, when it is activated, gives us the experience that we all share of the rich, three-dimensional, colorful world" (2001, p. 939), and that "cortical maps - those cortical areas where information seems to be retinotopically organized - might appear to be good candidates for the locus of perception." (2001, p. 939). O'Regan and Noë also refer to this view saying that it is a "theory of vision in which there is a picture-like internal representation of the outside world" (2001, p. 953), or "an internal, more or less picture-like, representation of the visual world." (2001, p. 955).

O'Regan and Noë consider this view as part of a broader approach to the relationship between brain and consciousness, according to which "consciousness is an intrinsic property of neural states", which would have "an additional property of being phenomenologically conscious." (2001, p. 965). In other words, a "set of neurons" or "neural representations" would correlate "strongly with aware perceptual states", and this would happen "because these neurons are probably linked to the mechanisms that are generating awareness" (2001, p. 966). Thus, "the discovery of perfect correlation would give us reason to believe that we had discovered the neural activity sufficient to produce the experience." (2001, p. 967). From this view of the brain-consciousness relationship, the problem of consciousness would be "to understand what processes or mechanisms or events in the brain make certain contents phenomenologically conscious" and "where, and how, does consciousness happen in the brain." (2001, p. 965).

O'Regan and Noë do not think that this is the main problem of consciousness, at least, from a philosophical perspective. Taking visual consciousness as a paradigmatic example, they agree that there are cortical maps, retinotopically organized, which contain information about the visual world. However, its presence and particular organization "can neither in itself explain the metric quality of visual phenomenology" nor "why an activation of cortical maps should produce visual experience." (2001, p. 939). O'Regan and Noë believe that a perfect correlation between visual consciousness and a set of neurons would just show that the "neural activity played some role in vision", whithout explaning why or how this neural activity produces that particular experience: 
suppose we were to discover that in the pineal gland of macaque monkeys there was a tiny projection room in which what is seen by the monkey was projected onto an internal screen whose activity correlated perfectly with the monkey's visual awareness. On reflection it is clear that such a discovery (which would surely be the Holy Grail of a neural correlate of consciousness seeker!) would not bring us any closer to understanding how monkeys see. For we would still lack an explanation of how the image in the pineal gland generates seeing; that is, how it enables or controls or modulates the forms of activity in which seeing consists. (2001, p. 966-967).

O'Regan and Noë refer to the problem of brain-consciousness relationship as the "qualia problem", being qualia "frequently characterized as the 'phenomenal', or 'qualitative,' or 'intrinsic' properties of experience", known through introspection and being "typically contrasted with 'intentional' or 'representational' or 'functional' features." (2001, p. 960). Considering roughly that qualia would be the ways in which we experience something subjectively, the qualia problem, also known as the "explanatory gap", would consist in connecting subjective and objective states/processes: "It has been suggested on this point that there is an unbridgeable 'explanatory gap', that it is not possible to explain the subjective, felt aspects of experience in behavioral, physical or functional terms" (2001, p. 960). In a more recent paper, "Sensorimotor theory of consciousness", published in 2015, Kevin O'Regan and Jan Degenaar, quoting Joseph Levine, refer to the explanatory gap in somewhat different terms. Adding the notion of "description", they say that the "challenge in explaining the quality of experience is to avoid an 'explanatory gap' between descriptions of the biological or physical processes involved in experience and descriptions of the phenomenal quality of experience." (2015, p. 2).

\section{2}

To avoid the qualia problem, or the explanatory gap, O'Regan and Noë argue that qualia, understood as "properties of experiential states or events" (2001, p. 960) or occurrences, do not exist. However, by denying the existence of qualia as just defined, the authors "are not denying that experience has a qualitative character" (2001, p. 960), but a sort of passive way of thinking about it: "Our claim, rather, is that it is confused to think of the qualitative character of experience in terms of the occurrence of something (whether in the mind or brain)." (2001, p. 960). O'Regan and Noë say both, that "scientists and philosophers frequently get the phenomenology of experience wrong; they misdescribe what perceptual experience is like" (2001, p. 960), and that "by denying the need for qualia we are not denying the existence of perceptual experience, or the possibility of phenomenological reflection on experience." (2001, p. 971).

Consistent with this claim O'Regan and Noë declare their great sympathy for the phenomenological tradition of Husserl and Merleau-Ponty, who presented "a clear and rigorous conception of the methodology of first-person investigations

of experience" (2001, p. 973), and "make contributions toward the development of 
a first-person study of consciousness which does not rely on the problematic conception of qualia criticized above" (2001, p. 973). Thus, O'Regan and Noë argue for "a more full-blooded phenomenological project" (2001, p. 973), defending a phenomenological approach which they believe "provides an account of the subject matter of phenomenology that is superior to that put forward by qualiaoriented positions" (2001, p. 962). Superior in two fundamental aspects: first, because it would be a theory "supported by careful reflection on what it is like to have perceptual experience" (2001, p. 962), which would exclude any conception that assumes the existence of a "detailed internal representation of the environment in the head." (2001, p. 962); second, differently from "traditional qualia-based approaches to experience", which "threaten to make experience itself something mysterious and inaccessible", the account to be proposed "helps place phenomenology as an undertaking on solid ground." (2001, p. 962).

But what rigorous description of experience would result from a phenomenology without qualia, as defined above? Before presenting O'Regan and Noe's answer to this question, it is necessary to clarify their use of the terms "consciousness" and "awareness", in order to understand what they mean by subjective and qualitative aspects of experience. By defining consciousness as transitive consciousness, or consciousness of, from the visual consciousness case, the authors say that being transitively conscious is to be aware of a feature of a scene, meaning that it is not an unconscious automatic exercise, rather an activity involving attention, in the sense that it is integrated in the "current planning, reasoning and speech behavior". (2001, p. 960). O'Regan and Noë's example of a driver who drives a car while talking to a friend helps to clarify this point. When driving the car, although his brain is tuned to sensorimotor contingencies related to both the relevant features of the scene and his driving behavior, such as steering and speed adjustment, by talking to his friend, the driver would not be aware of most of those features. In other words, the driver would be acting as an automatic pilot controlling the flight of an airplane, that is, his behavior would be regulated by appropriate sensorimotor contingencies, but he would be visually unaware of the relevant characteristics of the scene. Differently, visual awareness comes into the picture when conscious attention for thought and planning is present: "But if you should turn your attentions to the color of the car ahead of you, and think about it, or discuss it with your friend, or use the knowledge of the car's color to influence decisions you are making, then, we would say, you are aware of it." (2001, p. 944).

After arguing that O'Regan and Noë use the terms "awareness" and "consciousness" meaning the qualitative and subjective aspects of conscious experience, I return to the question of the explanatory gap from the concept of qualia. First, as it was said before, O'Regan and Noë deny the existence of qualia, that is, they criticize the description of conscious experience intrinsic to the notion of qualia, and, consequently, the existence of an explanatory gap: "there is no explanatory gap because there is nothing answering to the theorist's notion of qualia. That is, we reject the conception of experience that is presupposed by the problem of the explanatory gap." (2001, p. 962). Second, as it was also said before, 
despite O'Regan and Noë's denying the existence of qualia, they argue that conscious experience has a qualitative character: "we can defend this claim even though we do not deny, as we have been at pains to explain above, that there are experiences and that experience has qualitative character." (2001, p. 963). Thus, the authors propose a "phenomenological reflection on experience" which "captures what we believe, as experiencers, about our experiential life, but does so in a manner that does not give rise to the mystery of the explanatory gap." (2001, p. 971).

Assuming, without further justification, that the traditional representationist approach creates, but does not solve, the explanatory gap problem, O'Regan and Noë claim to solve this problem with what they call "sensorimotor theory of consciousness", also termed "sensorimotor contingency theory." As it will be seen in the next section, it is with this theory that O'Regan and Noë try to explain both, the existence of particular forms of consciousness, taking visual consciousness as a paradigmatic instance, and the existence of consciousness in general, thus facing this "absolute question" from "comparative questions" such as: "What explains that some environmental properties are consciously experienced while others are not? What explains that we sometimes are conscious while in other cases we are not (e.g. knocked out)? What explains that some systems (e.g. humans) have conscious experience while others (e.g. thermostats) do not?" (2015, p. 4).

\section{THE SENSORIMOTOR CONTINGENCY THEORY AND THE EXPLANATORY GAP}

2.1

To overcome the explanatory gap, O'Regan and Noë propose, against the current "mysterious assumption", a "natural way" of addressing the "problems about the nature of visual consciousness, the qualitative character of visual experience, and the difference between vision and other sensory modalities." (2001, p. 940). Their view is centered on the idea that vision is an "exploratory activity" mediated by "sensorimotor contingencies": "a mode of exploration of the world that is mediated by knowledge of what we call sensorimotor contingencies." (2001, p. 940). What O'Regan and Noë mean by "sensorimotor contingency," is the "structure of the rules governing the sensory changes produced by various motor actions." (2001, p. 941). So, to have visual perception is the same as "being able to exercise control of the rules of sensorimotor contingency associated with vision" (2001, p. 943). These rules are also referred to as "laws".

The rules/laws related do visual consciousness would be both, those inherent to the body and those involving the relationship between the body and the outside environment. There is a rule/law governing the relationship between eye movements and retinal events: "when the eyes rotate, the sensory stimulation on the retina shifts and distorts in a very particular way, as determined by the size of the eye movement, the spherical shape of the retina, and the nature of the ocular

optics." (2001, p. 941). Another rule/law relates body movement to the pattern of flow on the retina: "the flow pattern on the retina is an expanding flow when the body moves forwards and contracting when the body moves backwards." (2001, 
p. 941). There is also a rule/law governing the relationship between the closing of the eyes during blinks causing the "stimulation to change drastically, becoming uniform (i.e. the retinal image goes blank)." (2001, p. 941). But the constitutive rules/laws of sensorimotor contingencies are not limited to the relations between the bodily components relevant to the visual consciousness; they also involve the properties of the objects and external environment. Thus, features such as size, shape, texture and color, as well as distances and angles relative to the observer, are objective aspects that should be considered as fundamental for visual consciousness, considering the limits of the constitutive information of the retinal image and its dependence on those elements external to the retinal image.

However, these rules/laws related to the body and the external environment would just be necessary conditions, not being sufficient to explain the conscious aspect of vision, which would also depend on the existence of purposes of "thinking", "planning", "reasoning" and "action guide". This third essential component for the existence of visual consciousness is presented by O'Regan and Noë with the example of driving a car. The idea is that when driving we are faced with a scenario whose sensorimotor contingencies are partly used to control our behavior, for example, to adjust the direction or speed of the car. It happens that, although we have our behavior regulated by this type of sensorimotor contingencies, we are often, in relation to them, as "automatic pilots controlling the flight of an airplane" (2001, p. 944), that is, we remain "visually unaware of the associated aspects of the scene." (2001, p. 944). Hence, in order to have visual awareness, it is necessary, "in addition to exercising the mastery of the relevant sensorimotor contingencies, to make use of this exercise for the purposes of thought and planning" (2001, p. 944), or, as it is also said by the authors, for the purposes of thought, control, reasoning and action. These three essential aspects of visual consciousness are summarized by O'Regan and Noë:

one important dimension of what it is like to see is fixed by the fact that there is a lawful relation of dependence between visual stimulation and what we do, and this lawful relation is determined by the character of the visual apparatus. A second crucial feature that contributes to what it is like to see is the fact that objects, when explored visually, present themselves to us as provoking sensorimotor contingencies of certain typically visual kinds, corresponding to visual attributes such as color, shape, texture, size, hidden and visible parts. Together, these first two aspects of seeing, namely, the visual-apparatus-related sensorimotor contingencies, are what make vision visual, rather than, say, tactile or auditory. Once these two aspects are in place, the third aspect of seeing, namely, visual awareness, would seem to account for just about all the rest of what goes into making up the character of seeing. For, visual awareness is precisely the availability of the kinds of features and processes making up the first two aspects for the purposes of control, thought, and action. (2001, p. 944).

But, how this approach, involving the three mentioned aspects of visual consciousness, contributes to overcoming the explanatory gap requires further explanation. O'Regan and Noë try to do that in the authors' response to open peer 
commentary, where they reply to the criticisms "by formulating more explicitly the reasoning implicit in the target text." (2001, p. 1011). There, they address the question, which they call "basic", that is, "can the sensorimotor approach explain why activity drawing on knowledge of sensorimotor contingencies gives rise to experience at all?" (2001, p. 1011). Their first step is to explain what they mean by the qualitative aspect of visual experience, or the what it is like to have a visual experience, in the sense proposed by Thomas Nagel in the article "What is it like to be a bat?". They consider that the defining features of the qualitative aspect that need to be explained by the sensorimotor approach are the following: visualness, forcible presence, ongoingness and ineffability. Let's see how O'Regan and Noë define and explain each one of these features of visual conscious experience.

Regarding the first aspect, that is, the visualness of conscious experience, the authors believe that what makes it visual and non-auditory, olfactory, tactile, etc., as I already said in the second section of this paper, is the specific sensorimotor contingencies "mediated by the visual apparatus and by the character of the sensory changes produced by objects as they move in space." (2001, p. 1012). It can be inferred from this that something similar happens with conscious auditory, olfactory, tactile, etc. experiences, with the difference that the mediation would involve other sensory and environmental devices related to these different modalities.

The second aspect of visual conscious experience, the forcible presence, is explained by two notions: grabbiness and bodiliness. Grabbiness means that an object forces its presence to become conscious to the perceiver, thus attracting his attention. Bodiliness means that the sensory stimulation coming from an object changes as we move the whole body, or parts of it, such as the eyes and head, relevant to the perception of that object. Grabiness and bodiliness would also explain the third aspect of conscious experience, that is, the feeling of an ongoing qualitative state. The awareness of experience as ongoingness would result from the fact that sensory events are always present when we look at them, that is, when they attract our attention, and vary regularly according to our bodily movements.

The fourth aspect of visual conscious experience to be explained is the fact that conscious experience appears to us as ineffable. This sense of ineffability would be the result of our ignorance on the complex sensorimotor laws that govern it, for example, the complex processes involving the functioning of the eye and its relation to visual stimuli are not consciously available to us, thus impossible to be described, although possible to be used: "our sense of the ineffability of experience is explained by the fact that we lack access to the very complicated laws governing the sensorimotor contingencies involved in sensorimotor exploration." (2001, p. 1012).

I would like to finish this section by making a brief comment about the role of the brain in the sensorimotor contingency theory. By distinguishing the visual contingencies related to the visual apparatus and objects from the processes of thought, planning, reasoning and control, O'Regan and Noë mention the involvement of the brain only with the first two necessary but not sufficient elements of visual consciousness. They say that the function of the brain is to 
encode the visual attributes according to the vision-specific laws of sensorimotor contingency. In the case of the visual quality of shape, for example, the brain would abstract from the infinite "set of all potential distortions that the shape undergoes when it is moved relative to us, or when we move relative to it [...] a series of laws, and it is this series of laws which codes shape." (2001, p. 942). The same reasoning is applied to other kinds of visual quality, it being the role of the brain, in this practical and non-propositional knowledge, to extract the laws that are archived and applicable whenever new visual stimuli are present.

Thus, in specifying the role of the brain in visual consciousness, O'Regan and Noë restate their position critical of the traditional neuroscientific view according to which the content of visual experience would be generated by the activation of specific neural substrates. Strictly speaking, there would be no neural substrates specific to vision, since the specification of visual contents would depend on the knowledge of sensorimotor contingencies involving the interaction between the visual apparatus and the environment. By assuming that conscious visual experience consists of an activity of exploring the environment, the authors argue that visual experience is not an "occurrence" derived from neural activity of the brain, the role of this organ being only "the mastery and exercise of the laws of the sensorimotor contingency." (2001, p. 968). Thus, the brain is considered just as "an element in a system, and not, as it were, as the seat of vision and consciousness all by itself." (2001, p. 970).

\section{2}

O'Regan and Noë believe that the sensorimotor contingency theory above summarized, is good enough to explain the qualitative character of conscious experience, that is, to explain why a sensation has a feel and why this feel has particular features in each distinct sensation, thus solving the problem of the explanatory gap: "that is, the problem of explaining perception, consciousness, and qualia in terms of physical and functional properties of perceptual systems" (2001, p. 1020). But, for reasons such as those we will see next, some philosophers do not agree with O'Regan and Noë, arguing that their view is not very successful in overcoming the explanatory gap problem.

As it was said at the beginning of the first section, the 2001 paper by O'Regan and Noë was published along with numerous comments, many of them objections, and the authors' responses. Here I highlight just a few among the many critical comments, namely those centered on the notion of qualia and the problem of the explanatory gap. Regarding the question of qualia, a fundamental point concerns how O'Regan and Noë understand it. As it was shown in the first section, they do not accept the existence of qualia, defined as internal conscious subjective states/events/occurrences produced by the brain, although they defend the existence of conscious subjective experiences, which have a qualitative character and are amenable to a phenomenological description. Thus, it can be stated that the sensorimotor contingency theory is not a view of the mind-body relationship that proposes to reduce conscious mind to physical and/or functional and/or 
behavioral events/processes. And it is from this interpretation that some critics argue that O'Regan and Noë have failed in their effort to overcome the explanatory gap, as will be seen next.

Andy Clark and Josefa Toribio, for example, agree with O'Regan and Noë's emphasis on the intimate relationship between conscious content and embedded action, but disagree that they have succeeded in dissolving or avoiding the "hard problem". Thinking of the case of vision, it could be said that a robot that is an excellent ping-pong player would meet the conditions established by the sensorimotor contingency theory - the use of visual stimuli, the learning of visual sensory-motor contingencies and the goal of winning -, but that would not imply that this robot has some kind of conscious visual experience: "Surely someone could accept all that O\&N offer, but treat it simply as an account of how certain visual experiences get their contents, rather than as a dissolution of the so-called hard problem of visual qualia." (2001, p. 979).

Martin Kurthen does not understand how O'Regan and Noë can reject qualia, understood as states/occurrences, but maintain the existence of experiences with qualitative character understood as ways of acting. If experience has a qualitative/phenomenal feature "then the gap opens between these features and the ways of acting they are meant to be identified with" (2001, p. 990), that is, "by merely postulating an identity of action and visual consciousness, they will not escape the explanatory gap problem, since 'ways of acting' are by no means closer to experiential features than 'internal representations' are." (2001, p. 990). Strictly speaking, the theory of sensorimotor contingencies does not answer the fundamental question: "why should skilled exercise generate phenomenal consciousness at all?". (2001, p. 991). So, "to dismiss qualia in favor of ways of acting, will not suffice to avoid the gap as long as the existence of experiences with qualitative character is affirmed." (2001, p. 991).

Klaus Oberauer agrees with this criticism by saying that the theory proposed by O'Regan and Noë "is in a no better position than any other theory to solve the 'hard problem' of consciousness." (2001, p. 996). He begins his comments by questioning the thesis that qualia, defined as "properties of experiential states or events", is an illusion, after all, by characterizing experiences as "modes of act" or "things we do", even they are not "states", "they certainly are events", that is, "it seems completely reasonable to characterize qualia as features of events going on during perceptual activity." (2001, p. 996). Hence, to say that experience could not be characterized as something static (state) does not imply that the term qualia is devoid of meaning, which can be understood as "a descriptive term that captures the fact that we experience something while we perceive, and that this experience has a certain quality that could be different for different people even if we perceived (in an information-processing sense) the same thing." (2001, p. 996). Like Clark and Toribio, Oberauer thinks that if qualia, as just defined, could be explained from sensorimotor contingencies, there would be a logical necessity for it to occur whenever sensorimotor contingencies were present, what implies that if there were a robot with appropriate sensorimotor contingencies, necessarily this 
machine would have a "rich inner life". Oberauer concludes by ironically saying that he stays "agnostic on this, even for a very graceful robot." (2001, p. 996).

According to the criticisms previously summarized, O'Regan and Noë misunderstood the notion of qualia, and consequently the problem of the explanatory gap. Following these criticisms I think that all that O'Regan and Noë accomplished was to establish the essential role of the environment, the body (brain included), and action to the existence and nature of the contents of visual sensations, offering a way of thinking about the existence of all forms and contents of consciousness. But this could be accepted even by those who, like me, believe that the conscious mind is a property of the brain. I think, as I will argue throughout next section, that it is possible intelligibly to address the problem of explanatory gap by considering the embodied and situated brain as the organ of consciousness.

\section{VISUAL CONSCIOUSNESS, BRAIN, BODY, ENVIRONMENT AND ACIION: ADDRESSING THE EXPLANATORY GAP}

\section{1}

By assuming that consciousness is a nonphysical, qualitative, and subjective property of the embodied and situated brain, two problems involving the relationship between brain and consciousness are constitutive of the explanatory gap, namely, that of explaining how the brain causes consciousness - upward causation -, and how consciousness causes brain events - downward causation.

Regarding the first problem, the main difficulty is to explain how the structural and functional complexity of the brain are causally related to the existence of consciousness in general, and, particularly, to specific forms and contents of consciousness. While currently available technologies are contributing significantly to such understanding, deeper knowledge depends on the development of even more sophisticated technologies, which will probably be available in the coming years. If the advance of knowledge of the structure and functioning of the brain related to consciousness will meet limits, this will be due to limits of technological development. If we believe that this gap is insurmountable because of the way our cognition works, so the explanatory gap would not be a unique to that psychophysical relationship, but intrinsic to scientific explanations in general, at least if it is assumed that the scientific solution to a problem consists in identifying spatial and/or temporal correlations between phenomena that precede and/or follow each other regularly, as we learn with David Hume. If the scientific procedure is appropriate for dealing with physical entities/processes, it is also legitimate for handling the relationship between brain and consciousness. As David Chalmers says:

There is a system of laws that ensures that a given physical configuration will be accompanied by a given experience, just as there are laws that dictate that a given physical object will gravitationally affect others in a certain way. It might be objected that this does not tell us what the connection is, or how a physical configuration gives rise to experience. But the search for such a 
connection is misguided. Even with fundamental physical laws, we cannot find a "connection" that does the work. Things simply happen in accordance with the law; beyond a certain point, there is no asking "how". As Hume showed, the quest for such ultimate connections is fruitless. If there are indeed such connections, they are entirely mysterious in both the physical and psychophysical cases, so the latter poses no special problem here.

It is notable that Newton's opponents made a similar objection to his theory of gravitation: How does one body exert a force on another far away? But the force of the question dissolved over time. We have learned to live with taking certain things as fundamental. (1996, p. 170).

Accepting the legitimacy of this explanatory model, according to which we should not look for an ultimate element that connects events, I present below an outline of a neuroscientific view, according to which visual consciousness is a property of the brain derived from its relationship with the body where it is embodied, and with the environment where brain and body are situated. According to that view, the external physical environment provides not only the objects visually perceived, but also the light, which, reflected by these objects, makes it possible to see them, being thus essential for perceiving colors, shapes, depth, movement, etc. The eye, whose structure is highly complex - pupil, iris, cornea, anterior and posterior chambers, crystalline, and the retina with its sophisticated and complex cellular/molecular constituents, etc.-, is also notoriously indispensable for the existence and characteristics of visual experience, since it allows the capturing of the light reflected by external objects, and from it, other of their properties such as color, form, depth, movement, etc. As is widely known, if the visual organ has some structural and/or functional problem, the quality of the visual experience is affected, as exemplified by cases such as myopia, astigmatism, presbyopia, amblyopia, cataracts, color blindness, total blindness, etc. Besides, it could not be ignored how necessary are specific ocular movements - saccadic and extraocular muscles movements - to make possible the visual consciousness.

What about the role of the brain in visual consciousness? Certainly, it is not possible, and not even necessary, to present in the short space of this paper everything that is already known, and how much is not known about the visual brain. So I will summarize it by saying that from the retina - composed of photoreceptor cells (cones and rods), as well as horizontal, bipolar, amacrine, ganglion, etc. cells - information is transmitted by the nerve and optic structures, such as the lateral geniculate nucleus with its optical radiations, towards the visual cortex, with its several nuclei (V1, V2, etc.) responsible for specific visual functions, and toward areas such as frontal ocular field, superior colliculus, pretectal nuclei, extraocular muscles, etc. The microscopic and macroscopic recording of activities of these structures, and the observation of what happens to the contents of visual consciousness when they are affected by lesions, pharmacological interventions, electromagnetic, etc., has permitted the identification of the function of each one of them, isolated or together, related to the generation of both, the most basic sensory characteristics of visual consciousness, such as color, shape, movement, 
spatial location, identification of objects, etc., as well as to the motor processes, also necessary for the generation of those visual contents.

So, I am assuming that this is the direction to be followed by nonreductionist physicalists to explain how the brain, from its interaction with the other parts of the body and with the environment outside the body, produces visual consciousness. In this sense, the difficult problem to be solved, the first aspect of the explanatory gap, is a scientific problem, which refers to the knowledge of the details of the brain structure and functioning responsible for the several aspects of visual consciousness.

\section{2}

The other difficult problem, the second aspect of the explanatory gap, the downward causation problem, still taking visual consciousness as a paradigmatic example, can be formulated as follows: How does visual consciousness, being a nonphysical, qualitative and subjective property of the brain, cause brain events? I have argued (COELHO, 2017) that this sort of formulation of the problem of mental causation, paradigmatically presented by Jaegwon Kim (1998), is an important part of the problem itself. Intrinsic to that formulation is the idea that consciousness is a nonphysical (immaterial) Cartesian substance, ${ }^{2}$ or a property of a nonphysical (immaterial) Cartesian substance, which would causally affect the brain. Hence the Cartesian problem: How does a nonphysical (immaterial) substance act causally on a physical (material) substance?

I think that this problem would not arise if visual consciousness was neither considered as a nonphysical substance, nor as a property of a nonphysical substance, but rather as a nonphysical property of the brain, which gives the brain skills that it would not have without visual consciousness. Consciousness in general, and visual consciousness in particular, would be a sort of guide that the brain uses to interact with the body in which it is embodied, and through its body, to interact with the outside world in which brain and body are situated. So the relationship between visual consciousness, brain, body and external world could be summarized as follows: An embodied brain receives, through the eyes, physical stimuli from the external environment from which the brain not only produces the forms and contents of its visual consciousness, but also uses them to guide its embodied movements in the outside environment in which it is situated. The visual consciousness would be for the brain something like the light of a flashlight is to an individual in a dark environment. The flashlight produces the visibility that the individual uses as a guide from which he moves the flashlight creating other

\footnotetext{
${ }^{2}$ In Article 51 of "Les Principes de la Philosophie", Descartes defines substance as the existing being that does not depend on another being to exist, that is, that is not an attribute of another existing being; on the contrary, it serves as the substrate or support of other existing beings, which would be its attributes: "When we conceive the substance, we conceive only a thing that exists in such a way that it only needs its own to exist." (DESCARTES, p. 594). Article 52 presents the same position, only adding that the substance is a divine creation that does not depend on another divine creation: "to understand what substances are, it suffices only to see that they can exist without the help of anything else created." (DESCARTES, p. 594).
} 
visibilities and so on, in such a way that this allows him to move safely in his environment. Although the individual depends on the flashlight and on the light produced by it to move safely in his environment, it is the individual that moves and guides the flashlight and not the flashlight, let alone the light that moves or guides him.

How could this analogy help us to understand the relationship between the visual consciousness and the brain, considering the conscious mind essential for survival, although not exerting downward causal action? First, let us consider the difference. In the flashlight case there is a relationship between the individual, the flashlight and the light in which the individual, by turning on the flashlight, only indirectly produces the light that he uses, since, strictly speaking, it is the flashlight that produces the light. Considering the light (visibility) as if it were the visual consciousness, the eye as if it were the flashlight and the brain as if it were the individual, the brain and not the eye is what creates visual consciousness (the individual, not the flashlight) from the environmental stimuli captured and transmitted by the eye. Second, let us consider the similarity. Just as the light (visibility) produced by the flashlight is used by the individual as a guide, the visual consciousness produced by the brain is also used by the brain as a guide to act adaptively, through its body, in the outside environment. The actions implemented by the brain upon the body, and throughout the body upon the external environment, from the forms and contents of its visual consciousness, allow it to receive other visual stimuli, which produce other brain events, generating other forms and contents of visual consciousness (new visibilities), which will be used by the brain as guides for new actions in the outside world, and so on.

I believe that the view presented in this section constitutes an intelligible way to address the problem of the explanatory gap, preserving the idea that consciousness has a subjective and qualitative nature produced by the brain from its interaction with its body (including bodily movements) and with the environment outside the body. In this sense, I find it promising to pursue the idea that the brain is the true agent -it is the brain that makes decisions, initiates and supports actions -, which uses the several forms and contents of its conscious mind - memory, belief, intention, volition, emotion, imagination, etc. - as a guide to initiate and maintain actions in the world. The fact that the brain is the agent does not diminish the relevance of the conscious mind, it does not make it an epiphenomenon of the brain, since without the conscious mind the brain would not be, structurally and functionally, what it is - as I have argued in COELHO, 2018) - , and it would not be able to do what it does. I am assuming that the conscious mind is a phenotype created by biological evolution, a property of the brain, which results from its interaction with the body and the external environment, used by the brain as a guide that allows it to act adaptively in the world. I believe that this view is a reasonable path to address the problem of the relationship between the conscious mind and the body, by moving away from the spell of the explanatory gap. 


\section{REFERENCES}

CHALMERS, David. The conscious mind: In search of a fundamental theory. New York/Oxford: Oxford University Press, 1996.

CLARK, Andy; TORIBIO, Josefa. Sensorimotor chauvinism? Behavioral and Brain Sciences, v. 24, n. 5, Oct. 2001, pp. 979 - 980.

COELHO, Jonas Gonçalves. A double face view on mind-brain relationship: the problem of mental causation. Trans/Form/Ação, v. 40, n. 3, p, 197-220, 2017.

Abordagem dupla face da relação mente consciente e cérebro: a visão como exemplo paradigmático. In: TOLEDO, Gustavo Leal; GOUVEA, Rodrigo A.; ALVES, Marco Aurélio S. (Orgs.). Debates contemporâneos em filosofia da mente. São Paulo: FiloCzar, 2018. p. 131-150.

DEGENAAR, Jan; O'REGAN, J. Kevin. Sensorimotor theory of consciousness. Scholarpedia, v. 10, n. 5, 2015, p. 4952. Available at: http://www.scholarpedia.org/article/Sensorimotor_theory_of_consciousness.

DESCARTES, René. Les Principes de la philosophie. In: Oeuvres et Lettres. Paris: Librairie Gallimard, 1952.

HURLEY, Susan; NOË, Alva. Neural plasticity and consciousness. Biology and Philosophy, v. 18, n. 1, 2003, pp. 131-168.

KIM, Jaegwon. Mind in a physical world: an essay on the mind-body problem and mental causation. Cambridge: MIT Press, 1998.

KURTHEN, Martin. Consciousness as action: the eliminativist sirens are calling. Behavioral and Brain Sciences, v. 24, Oct. 2001, pp. 990-991.

LEVINE, Joseph. Materialism and qualia: the explanatory gap. Pacific Philosophical Quarterly, v. 64, n. 4, 1983, pp. 354-361.

NAGEL, Thomas. What is it like to be a bat? Philosophical Review, v. 83, n. 4, 1974, pp. $435-450$.

OBERAUER, Klaus. The explanatory gap is still there. Behavioral and Brain Sciences, v. 24, n. 5, Oct. 2001, p. 996-997.

O'REGAN, J. Kevin.; NOë, Alva. A sensorimotor account of vision and visual consciousness. Behavioral and Brain Sciences, v. 24, n. 5, Oct. 2001, pp. 939-1031.

Recebido em: 21-02-2019

Aceito para publicação em: 28-08-19 